\title{
Primary Renal Lymphoma: A Case Report
}

\author{
Mohammed Alagha ${ }^{1 *}$, Ramadan Algamal ${ }^{2}$, Belal Suliman ${ }^{1}$, Rami Ajjour $^{3}$, Mariam Mattar $^{4}$ \\ ${ }^{1}$ Department of Radiology, Al-Shifa Hospital, Gaza, Palestine. \\ 2Department of Radiology, Shibinalkom Hospital, Cairo, Egypt \\ ${ }^{3}$ Department of Radiology, Indonesian Hospital, Gaza, Palestine \\ ${ }^{4}$ Department of radiology, National cancer institute, Cairo, Egypt.
}

\section{"Corresponding author: Mohammed Alagha}

Department of Radiology

Al-Shifa Hospital

Gaza, Palestine

Received: December 27, 2018

Published : December 31, 2018

\begin{abstract}
Renal lymphoma rarely seen as a primary neoplasm of the kidney, it is often seen as a part of multisystem disseminated extranodal lymphoma, or as a tumor recurrence, also may be seen in immunocompromised patients. We report a case of an 80-year-old lady with primary renal lymphoma (PRL).
\end{abstract}

Keywords: $\mathrm{CT}$; Lymphoma; Kidney

Abbreviations: PRL: Primary Renal Lymphoma; SRL: Secondary Renal Lymphoma; IVC: Inferior Venal Cava; CECT: Contrast Enhance Computed Tomography; MPR:Multi-Planner Reconstruction; RCC: Renal Cell Carcinoma; INR: International

the mass was outside the collecting system (Figure 5).

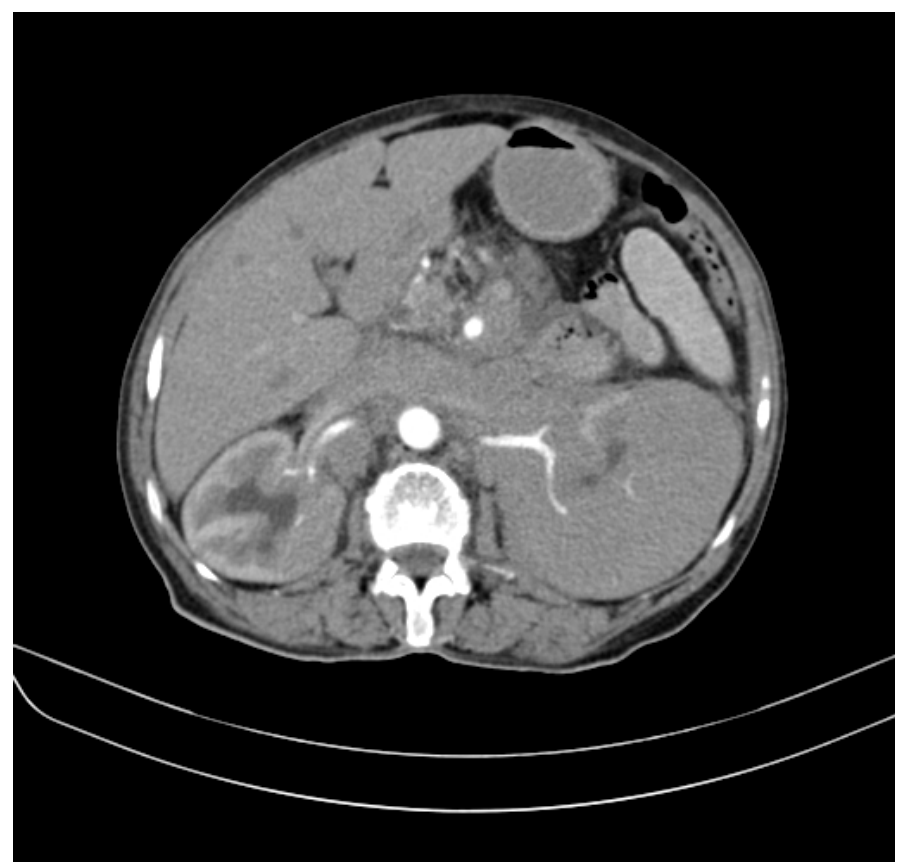

Figure 1: Axial CECT show minimally enhancing bilateral infiltrative renal masses encasing both renal parenchymas, notably the left, and extending to perinephric and retroperitoneal spaces, note the normal enhancing residual renal parenchyma. 


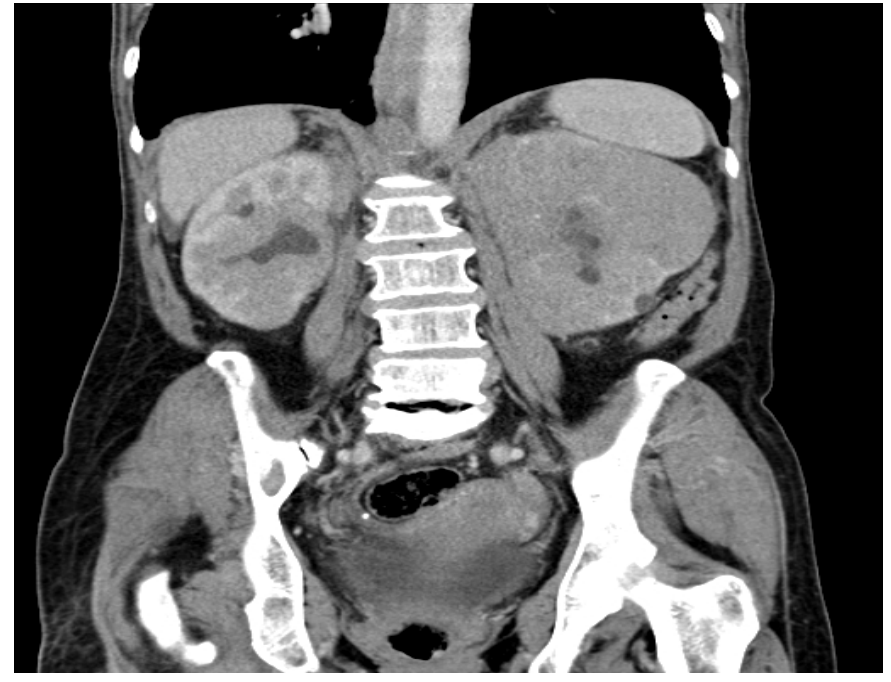

Figure 2: Coronal MPR CECT image show minimally enhancing bilateral infiltrative renal masses; invading both kidneys notably the left, extending to perinephric space with undisguised residual normal renal parenchyma, notably the right.

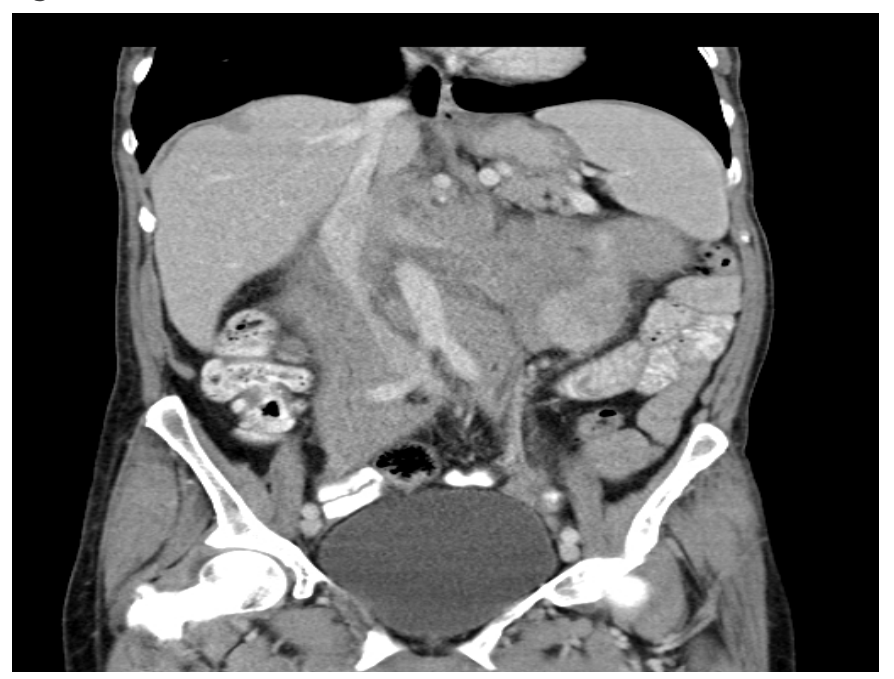

Figure 3: Coronal MPR CECT image show retroperitoneal molding of the lesion encasing the major vessels (including the aorta, iliac arteries, and IVC).

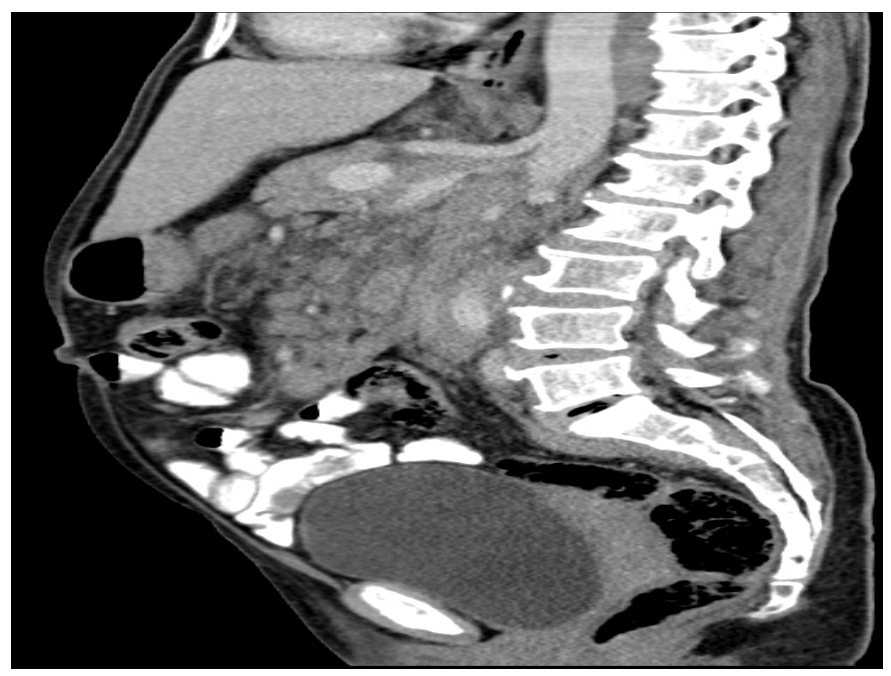

Figure 4: Sagittal MPR CECT shows retroperitoneal molding of the lesion encasing the aorta and its branches; SMA and coeliac trunk.

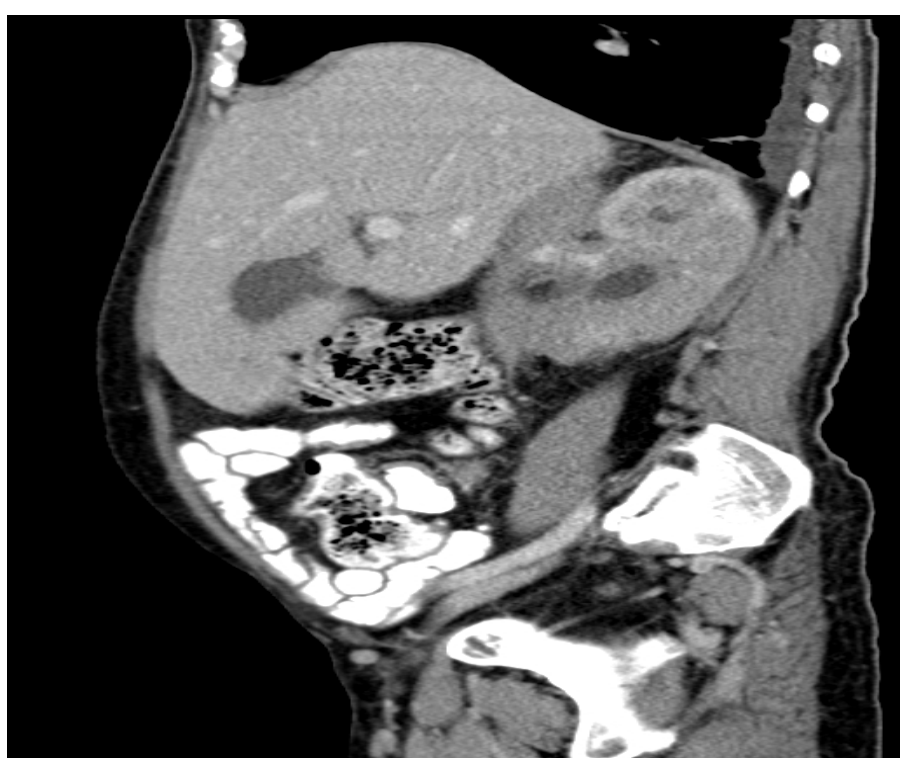

Figure 5: Sagittal MPR CECT shows infiltration of the right kidney.

The patient was referred to the Interventional Radiology unit for percutaneous core biopsy; the patient INR was within normal limits, an US-Guided core biopsy was done with a BRAD semiautomatic gun $\mathrm{G} 16 \times 15 \mathrm{~cm}$ and 2 samples were biopsied from the left renal mass, for further histopathological correlation, which confirmed PRL.

\section{Discussion}

Primary renal lymphomas (PRLs) is exceedingly rare [1-3], due to the fact that the kidneys, like the brain, lack lymphoid tissue which led many to question if it truly exists [4]. Multiple theories about its true origin, suggesting the renal capsule or the perinephric fat (being rich in lymphatic) hence it spreads to the renal parenchymal tissue [5], others postulated that it occurs due to chronic inflammatory process [6]. What is known and should be emphasized to diagnosis (PRLs) that it does not arise as an invasion from regional lymph nodes or associated with any other organs involvement as in secondary renal lymphoma (SRL) which is more common. PRLs account less than $1 \%$ of extranodal lymphomas [1-3]. It can be bilateral in $10 \%$ to $20 \%$ of cases. It is more common in $\mathrm{NHL}$ of B-cell type [7].

Clinical presentation is non-specific, fatigue, weight loss, flank pain, hematuria, proteinuria, and rarely acute renal failure form lymphomatous infiltration [8].

PRLs should be differentiated from renal cell carcinoma (RCC) 
in order to determine the method of treatment and to suggest a renal biopsy to avoid unnecessary nephrectomy [5].

Lymphomatous renal mass is typically homogeneous attenuation, hypovascular and demonstrates minimal enhancement following intravenous administration of contrast material, which may help differentiate lymphoma from the typically heterogeneous enhancing renal cell carcinoma. Nevertheless, a biopsy is often required for definitive diagnosis [1].

Being rare, few studies have described the imaging patterns of PRLs. Sporadic case studies and series from oncologic and urologic literature stated that PRLs may present similarly to SRL as focal masses (single or multiple); bilateral diffuse enlarged kidneys, or more often as large, ill-defined, infiltrative lesions engulfing the kidneys [8].

One major finding may help discriminate PRLs from RCC is that despite being aggressive it rarely involves the IVC, also the epicenter of the tumor being outside the collecting system help to differentiate it from urothelial carcinoma [9].

\section{Conclusion}

It is critical to differentiate by imaging RCC from Renal lymphoma, whether PRL or SRL, for proper management and to avoid unnecessary surgery. Nephrectomy is the treatment of choice for RCC while chemotherapy is for renal lymphoma.

\section{Teaching Point}

It is critical to differentiate by imaging RCC from Renal lymphoma, whether PRL or SRL, for proper management and to avoid unnecessary surgery. Nephrectomy is the treatment of choice for RCC while chemotherapy is for renal lymphoma.

\section{Authors' contributions}

Dr. Mohammed Alagha: Performed the physical exam, ultrasound examination, gathered scientific material, follow up with the patient and wrote down the manuscript.

Dr.Ramadan Algamal and Dr. Belal Suliman: Reviewed the manuscript and scientific data.

Dr. Rami Ajjour; Interpreted the CT study and perform the percutaneous core biopsy.

\section{Disclosures}

Authors do not have any disclosures.

\section{Consent}

Did the author obtain written informed consent from the patient for submission of this manuscript for publication? Yes

\section{Human and animal rights}

Ethical standards followed the responsible committee on human experimentation (institutional and national) and with the Helsinki Declaration of 1975, as revised in 2000 (5).

\section{References}

1. Sheth SH, Ali SY, Fishman EL (2006) Imaging of renal Lymphoma: Patterns of Disease with pathologic correlation. RadioGraphics 26(4): 1151-1168.

2. Kandel LB, McCullough DL, Harrison LH, Woodruff RD, Ahl ET Jr, et al. (1987) Primary renal lymphoma: Does it exist? Cancer 60(3): 386-391.

3. Okuno SH, Hoyer JD, Ristow K, Witzig TE (1995) Primary renal non-Hodgkin's lymphoma: An unusual extranodal site. Cancer 75(9): 2258-2261.

4. Olusanya AA, Huff G, Adeleye O, Faulkner M, Burnette R, Thompson H, et al. (2003) Primary renal non-Hodgkins lymphoma presenting with acute renal failure. J Natl Med Assoc 95(3): 220-224.

5. Ganeshan DH, Lyer RE, Devine CA, Bhosale PR, Paulson E (2013) Imaging of primary and secondary renal lymphoma. Am J Roentgenol 201(5): W712-W719.

6. Salem Y, Pagliaro LC, Manyak MJ (1993) Primary small noncleaved cell lymphoma of kidney. Urology 42(3): 331-335.

7. Zukotynski K, Lewis A, O'Regan K, Jacene H, Sakellis C, Almodovar S, et al. (2012) PET/CT and renal pathology: a blind spot for radiologists? Part 2. Lymphoma, leukemia, and metastatic disease. AJR Am J Roentgenol 199(2): W168-W174.

8. Choi JH, Choi GB, Shim KN, Sung SH, Han WS, Baek SY (1997) Bilateral primary renal non-Hodgkin's lymphoma presenting with acute renal failure: Successful treatment with systemic chemotherapy. Acta Haematol 97(4): 231235.

9. Sawa N, Ubara $Y$, Katori H, Hoshino J, Suwabe T, Tagami T, et al. (2007) Renal intravascular large B-cell lymphoma localized only within peritubular capillaries: Report of a case. Intern Med 46(10): 657-662.

Copyright: $\odot 2018$ Alagha M, et al. This is an open-access article distributed under the terms of the Creative Commons Attribution License, which permits unrestricted use, distribution, and reproduction in any medium, provided the original author and source are credited. 